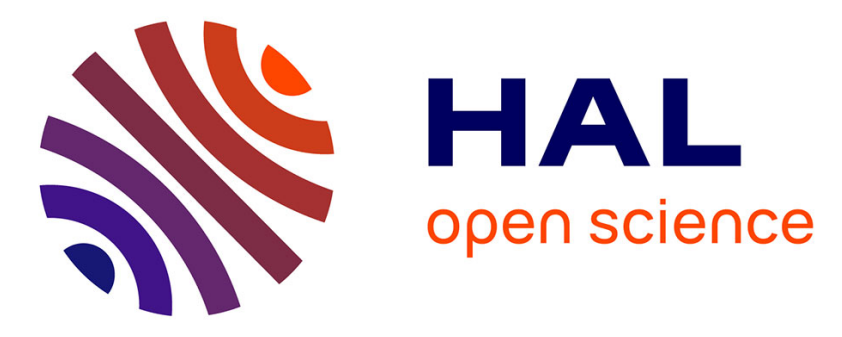

\title{
Novel erbia-yttria co-doped zirconia fluorescent thermal history sensor
}

\author{
Etienne Copin, X. Massol, Stéphane Amiel, Thierry Sentenac, Yannick Le \\ Maoult, Philippe Lours
}

\section{- To cite this version:}

Etienne Copin, X. Massol, Stéphane Amiel, Thierry Sentenac, Yannick Le Maoult, et al.. Novel erbiayttria co-doped zirconia fluorescent thermal history sensor. Smart Materials and Structures, 2017, 26 (1), art. 015001-11 p. 10.1088/0964-1726/26/1/015001 . hal-01620035

\section{HAL Id: hal-01620035 https://hal.science/hal-01620035}

Submitted on 11 Jan 2019

HAL is a multi-disciplinary open access archive for the deposit and dissemination of scientific research documents, whether they are published or not. The documents may come from teaching and research institutions in France or abroad, or from public or private research centers.
L'archive ouverte pluridisciplinaire HAL, est destinée au dépôt et à la diffusion de documents scientifiques de niveau recherche, publiés ou non, émanant des établissements d'enseignement et de recherche français ou étrangers, des laboratoires publics ou privés. 


\title{
Novel erbia-yttria co-doped zirconia fluorescent thermal history sensor
}

\author{
E B Copin, X Massol, S Amiel, T Sentenac, Y Le Maoult and P Lours \\ Université de Toulouse; CNRS, Mines Albi, INSA, UPS, ISAE-SUPAERO; ICA (Institut Clément Ader); \\ Campus Jarlard, F-81013 Albi, France \\ E-mail: etienne.copin@mines-albi.fr
}

\begin{abstract}
Thermochromic pigments are commonly used for off-line temperature mapping on components from systems operating at a temperature higher than $1073 \mathrm{~K}$. However, their temperature resolution is often limited by the discrete number of color transitions they offer. This paper investigates the potential of erbia-yttria co-doped zirconia as a florescent thermal history sensor alternative to thermochromic pigments. Samples of yttria-stabilized zirconia powder (YSZ, $8.3 \mathrm{~mol} \% \mathrm{YO}_{1.5}$ ) doped with $1.5 \mathrm{~mol} \% \mathrm{ErO}_{1.5}$ and synthesized by a sol-gel route are calcined for 15 minutes under isothermal conditions between 1173 and $1423 \mathrm{~K}$. The effects of temperature on their crystal structure and room temperature fluorescence properties are then studied. Results show a steady increase of the crystallinity of the powders with temperature, causing a significant and permanent increase of the emission intensity and fluorescence lifetime which could be used to determine temperature with a calculated theoretical resolution lower than $1 \mathrm{~K}$ for intensity. The intensity ratio obtained using a temperature insensitive YSZ:Eu ${ }^{3+}$ reference phosphor is proposed as a more robust parameter regarding experimental conditions for determining thermal history. Finally, the possibilities for integrating this fluorescent marker into sol-gel deposited coatings for future practical thermal history sensing applications is also discussed.
\end{abstract}

Keywords: thermal history sensor, sol-gel, luminescence, temperature measurement

\section{Introduction}

The knowledge of the temperature of components subject to high-temperature environments is a key factor for the development and safe use of numerous systems such as boilers, chemical reactors, furnaces, engines and gas turbines, as it plays a critical role in many degradation mechanisms [1-4]. Temperature sensitive paints are the current mean for determining the thermal history of components in confined areas or in operating systems where the direct measurement of temperature over large surfaces is not possible or not convenient [5-8]. Following exposure to operating temperature for a known and short period of time under stationary conditions, these coatings allow to derive maps of temperature of exposure from the analysis, upon return at room temperature, of the thermoactivated color changes undergone by the embedded thermochromic pigments. However, the limited and discrete number of available color transitions distributed over wide temperature ranges of a few hundreds of degrees Celsius often limits the temperature resolution of these paints to a few tens of degrees or more. The analysis of the color changes can also be difficult and highly dependent on operator and observation conditions. At last, many of the compositions of such paints include chemical substances falling under the restriction of international regulations such as $\mathrm{REACH}$, further pushing the actors of the sector to develop alternative pigments.

One of the solutions under investigation over the last few years is the implementation of photoluminescent markers, whose luminescence emission properties are subjected to permanent evolutions with temperature and duration of exposure as a result of thermally activated microstructural or chemical changes occurring within the material [9-19]. With appropriate calibration, the changes observed in at least one luminescence characteristic can therefore be correlated back to the temperature to which the material has been subjected during a previous thermal event under controlled conditions. 
Contrary to the discrete changes typical of thermochromic paints, the evolution with temperature of the luminescence parameters may be in most cases continuous over the range of interest [12-16], thus allowing to monitor continuous spectrum of temperature rather than temperature thresholds. Luminescence parameters can also be measured quantitatively with no ambiguity using standard spectroscopic equipments, leading to potentially much higher resolution than thermochromic paints in the determination of temperature.

Recently, the Institut Clement Ader, in collaboration with the CIRIMAT, has developed the synthesis by a sol-gel process of yttria-stabilized zirconia (YSZ) based phosphors functionalized with lanthanide ions such as $\mathrm{Sm}^{3+}, \mathrm{Eu}^{3+}$ and $\mathrm{Er}^{3+}$ for future applications in temperature sensing within thermal barrier coatings for gas turbines [20-22]. These phosphors, not fully crystallized in the initial state, exhibit irreversible changes in their fluorescence properties after annealing in the range 1173-1373 K, suggesting they could be potentially used to record thermal history [20, 22].

This paper reports a study of the potential of an 8.25YSZ: $\mathrm{Er}^{3+}$ phosphor powder $\left(1.5 \mathrm{~mol} \% \mathrm{ErO}_{1.5}\right)$ synthesized by a sol-gel process as a fluorescent thermal history sensor in the temperature range $1173-1423 \mathrm{~K}$. The effect of a 15 minute-long exposure between 1173 and $1423 \mathrm{~K}$ on its crystal structure and fluorescence characteristics (spectra, intensity and decay time) is investigated in order to determine its sensitivity to thermal history in this temperature range. The robustness of an intensity ratio approach, using a temperature insensitive YSZ: $\mathrm{Eu}^{3+}$ phosphor as a reference, and the possibilities for integrating these fluorescent markers into coatings are then investigated and discussed in order to evaluate the relevance of this marker as an alternative to current thermochromic paints for future off-line temperature mapping applications.

\section{Fluorescent thermal history sensors: the choice of YSZ:Er ${ }^{3+}$}

The concept of fluorescent thermal history sensor is mainly based on the occurrence of thermally activated microstructural and/or chemical changes within the sensing material, that produce a permanent evolution in at least one of its fluorescence characteristics, which in turn is sufficient to derive the heating temperature from a past thermal event. Many physico-chemical changes can indeed have a significant impact on the energy level distribution of activators and on the probability of occurrence of radiative electronic transitions, thus affecting spectral (emission wavelength and intensity) and temporal (decay time) luminescence properties. Currently, four main temperature-driven mechanisms have been identified which, providing that they are achieved under controlled conditions (temperature and exposure time), can serve to determine thermal history: (i) phase transformations $[9,10,23]$, (ii) diffusion of activator or sensitizer/quencher species [12, 24], (iii) oxidation of activator ions [16-19] and (iv) crystallization of the host matrix [11-15, 25, 26]. The latter mechanism is of particular interest in the case of inorganic phosphors produced by a sol-gel process or many similar soft chemistry routes, since an amorphous or incomplete crystallized state is generally obtained due to the relatively low temperatures involved during their fabrication, typically lower than $873-1073 \mathrm{~K}$ [27-29]. The temperature dependence of the crystallization rate constant, that follows an Arrhenius type relation [30], predicts a strong dependence on temperature of the microstructural state of the material which might thus pass on its fluorescence properties. Numerous studies carried out on the lanthanide activator ions $\mathrm{Eu}^{3+}$ (in $\mathrm{Al}_{2} \mathrm{O}_{3}$ [14], $\mathrm{ZrO}_{2}$ [31], YAG [32], $\mathrm{Y}_{2} \mathrm{O}_{3}$ [13, 33, 34], $\mathrm{YVO}_{4}$ [35], $\mathrm{CaY}_{2} \mathrm{Si}_{3} \mathrm{O}_{12}$ [36]), $\mathrm{Er}^{3+}$ (in $\mathrm{SiO}_{2}$ [25], $\mathrm{GdAlO}_{3}$ [26], $\mathrm{ZrO}_{2}$ [37], $\mathrm{Gd}_{2} \mathrm{TiO}_{7}$ [38]), $\mathrm{Tb}^{3+}$ (in $\mathrm{Y}_{2} \mathrm{O}_{3}$ [14, 34], $\mathrm{Y}_{2} \mathrm{SiO}_{5}$ [12]), $\mathrm{Pr}^{3+}$ (in $\mathrm{PbO}-\mathrm{Sb}_{2} \mathrm{O}_{3}-\mathrm{B}_{2} \mathrm{O}_{3}$ [39]) and $\mathrm{Ce}^{3+}$ (in $\mathrm{YAG}$ [40]), have shown that their emission intensity at room temperature, initially nonexistent or weak, is greatly improved with the increase of crystallinity resulting from annealing at high temperature, typically in the range 1073-1573 K. This effect, that goes along with the sharpening of emission peaks and generally an increase of the luminescence lifetime [12$14,32,34,38]$, results mainly from the coarsening of the average crystal size, the uniformization of the crystal field as well as the reduction of the number of crystal defects and residual organic groups acting as luminescence quenchers [12, 33, 34, 38].

Figure 1 shows the $\mathrm{x}$-ray diffraction patterns and the fluorescence spectra of the YSZ: $\mathrm{Er}^{3+}$ phosphor powder produced by a sol-gel route at the Institut Clément Ader and CIRIMAT [21] in the initial state and after further annealing at $1373 \mathrm{~K}$ for $2 \mathrm{~h}$.

In the initial state, the $\mathrm{x}$-ray diffraction pattern in figure 1(a) is in good agreement with that of the metastable tetragonal phase $t^{\prime}$ of 10-YSZ (pattern \#01-082-1241 from the ICSD database), although the relatively weak and broad peaks indicate an incomplete crystallization with small average crystal size. At this stage, the powder produces very weak fluorescence emission lines for wavelengths at 545 and $562 \mathrm{~nm}$ originating from the ${ }^{4} \mathrm{~S}_{3 / 2} \rightarrow{ }^{4} \mathrm{I}_{15 / 2}$ transition of $\mathrm{Er}^{3+}$ under the excitation of a laser emitting at $532 \mathrm{~nm}$ (figure $1(\mathrm{~b})$ ). Annealing for $2 \mathrm{~h}$ at $1373 \mathrm{~K}$ leads to a significant increase of the diffraction peak intensity, to a reduction of the full width at half-maximum and to the deconvolution of the peak doublets at $2 \theta=35^{\circ}, 60^{\circ}, 74^{\circ}$, $84^{\circ}$ as a result of the enhancement of crystallinity and crystal growth (figure 1(a)). It also generates an increase by a factor of more than 50 of the emission lines intensity (figure 1(b)). Finally, the decay time of the peak at $562 \mathrm{~nm}$ is observed to increase from $\sim 16$ to $\sim 43 \mu \mathrm{s}$. Such pronounced behavior was not observed with $\mathrm{Sm}^{3+}, \mathrm{Eu}^{3+}$, $\mathrm{Dy}^{3+}$ and $\mathrm{Tm}^{3+}$ powders produced under the same conditions, for which the emission intensity increase after the enhancement of crystallinity was limited to a factor of 1.6 to $6[22]$.

Therefore, the specific energy level distribution of the $4 f$ orbitals of $\mathrm{Er}^{3+}$ ions [41], with no wide energy gap (figure 2), 

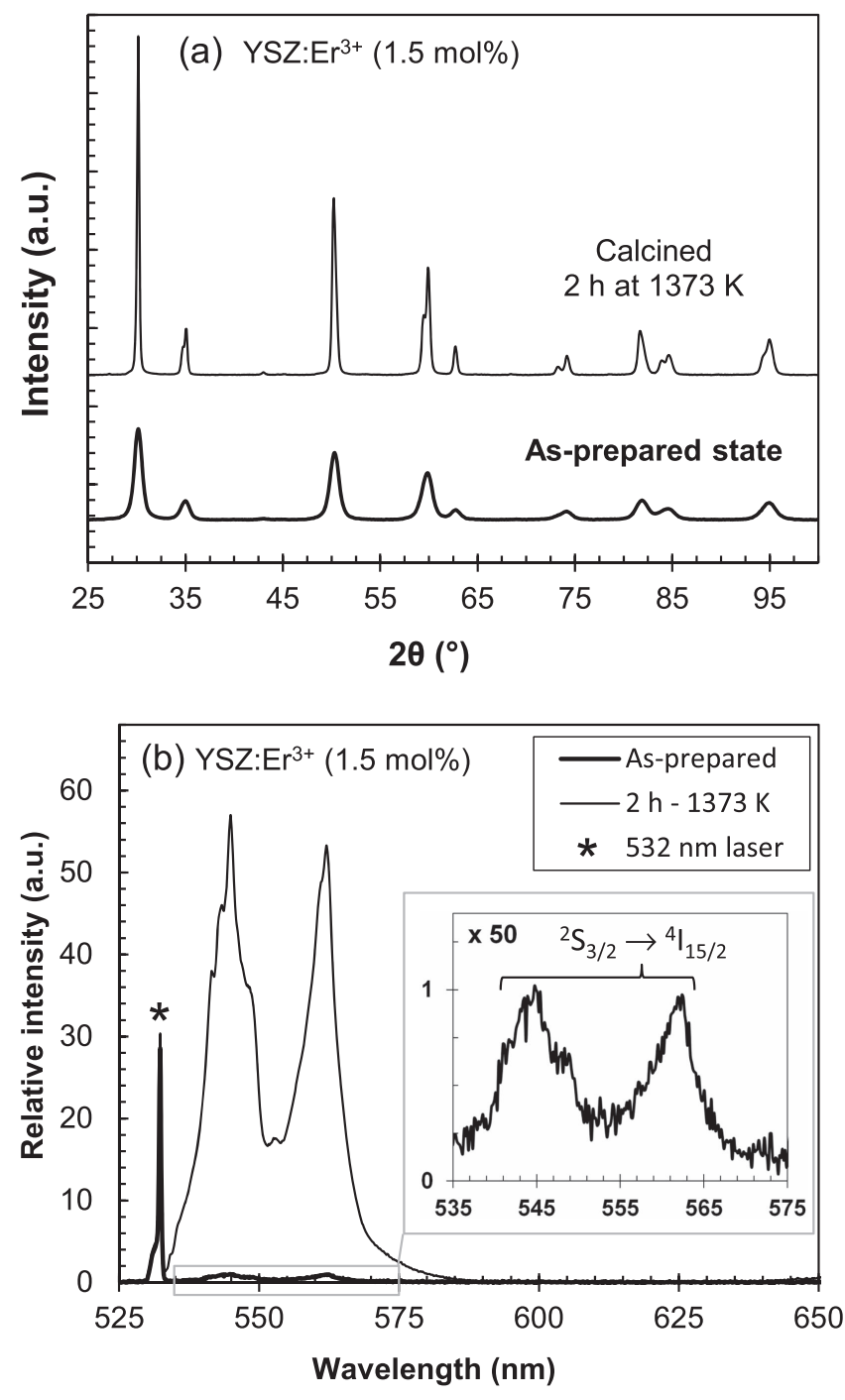

Figure 1. Comparison of (a) $x$-ray diffraction patterns and (b) fluorescence spectra of $1.5 \mathrm{~mol} \% \mathrm{Er}^{3+}$ doped YSZ powders synthesized by a sol-gel route in the as-prepared state (incomplete crystallization) and after $2 \mathrm{~h}$ annealing at $1373 \mathrm{~K}$.

is assumed to be at the origin of the particularly strong sensitivity of their emissions to the environment in this sol-gel synthesized host matrix. The presence of numerous and relatively close energy levels between the emitting states ${ }^{2} \mathrm{H}_{11 / 2}$ and ${ }^{4} \mathrm{~S}_{3 / 2}$ and the ground state ${ }^{4} \mathrm{I}_{15 / 2}$ might indeed promote quenching in this YSZ matrix by the way of energy transfers with crystal defects having high phonon energy, or with residual organic groups such as hydroxyl $\mathrm{HO}^{-}$, carbonate $\mathrm{CO}_{3}{ }^{-}$and nitrate $\mathrm{NO}_{3}{ }^{-}$groups found in materials processed at temperature lower than $1073 \mathrm{~K}$, to which $\mathrm{Er}^{3+}$ ions are particularly sensitive [38].

This work therefore proposes to investigate the extent of this temperature sensitivity in the context of short time heat treatments to assess for the thermal history sensing capability of this marker, which has the advantage to emit and to be readily excitable in the visible range as well as to be relatively easy to produce.

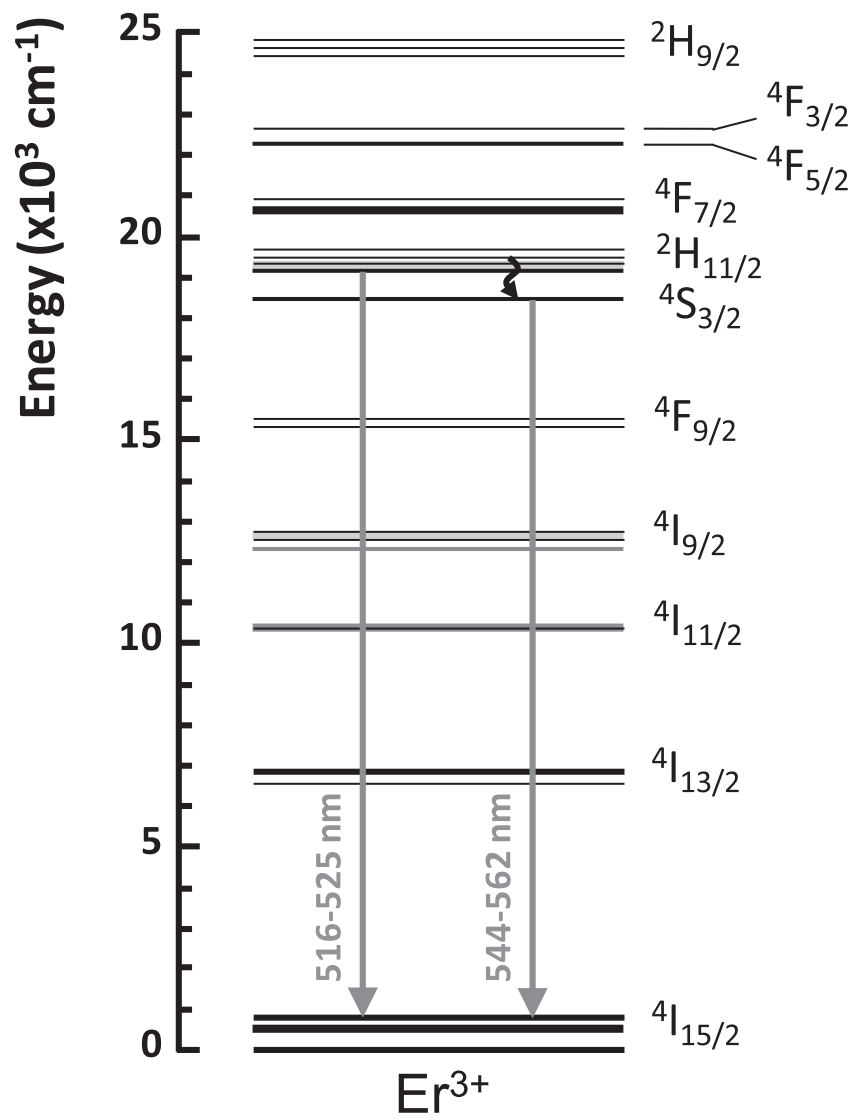

Figure 2. Energy diagram of the $4 f$ configuration of $\mathrm{Er}^{3+}$ free ion illustrating its two main radiative electronic transitions in YSZ [41].

\section{Methods}

8.3-YSZ: $\mathrm{Er}^{3+} \quad$ powder of composition $\left(\mathrm{YO}_{1.5}\right)_{0.083}\left(\mathrm{ErO}_{1.5}\right)_{0.015}\left(\mathrm{ZrO}_{2}\right)_{0.902}$ was synthesized by the sol-gel route developed in previous works [21, 22]. Samples of that powder were then calcined 15 minutes under isothermal conditions at different temperatures in the range 1173-1423 K with $50 \mathrm{~K}$ steps. This temperature range corresponds to the highest operating temperature range of YSZ-based thermal barrier coatings in gas turbines. The evolutions of the crystal structure and the fluorescence characteristics (emission intensity and decay time) of the samples were then investigated. Details about the preparation of the samples and their characterization can be found in the following paragraphs.

\subsection{Sol-gel synthesis and preparation of $\mathrm{YSZ}: \mathrm{Er}^{3+}$ phosphor powder}

YSZ: $\mathrm{Er}^{3+} \quad$ powder of composition $\left(\mathrm{YO}_{1.5}\right)_{0.083}\left(\mathrm{ErO}_{1.5}\right)_{0.015}\left(\mathrm{ZrO}_{2}\right)_{0.902}$ was synthesized by a solgel route using a protocol adapted from Lecomte et al $[42,43]$. The sol was prepared by mixing zirconium (IV) propoxide $\left(\mathrm{Zr}(\mathrm{OPr})_{4}\right)$ (Sigma Aldrich) and appropriate contents of yttrium (III) and Er (III) nitrates (Sigma Aldrich) as precursors in a solution of 1-propanol (Sigma Aldrich) and ultrapure water. Acetylacetone (AcAc, Sigma Aldrich) was used as a complexing agent to control the kinetics of hydrolysis of the zirconium alkoxide [44]. The volume rates of 
$\left[\mathrm{AcAc} / \mathrm{Zr}(\mathrm{OPr})_{4}\right]$ and $\left[\mathrm{H}_{2} \mathrm{O} / \mathrm{Zr}(\mathrm{OPr})_{4}\right]$ were kept constant at 0.8 and 9.5 respectively. More details about the preparation of the mixtures from the reagents can be found in reference [42]. After $30 \mathrm{~min}$ of mechanical stirring, the solution was then maintained for one night $(\sim 16 \mathrm{~h})$ at $323 \mathrm{~K}$ to accelerate the hydrolysis and condensation of the sol into a bright monolith gel free of precipitates. It was then dried above the supercritical point of 1-propanol $\left(T_{c}=534 \mathrm{~K} ; P_{c}=5.1 \mathrm{MPa}\right)$ in a stainless steel autoclave (Paar Instrument 4621). Temperature was kept constant at $543 \mathrm{~K}$ and pressure at $9 \mathrm{MPa}$ for $1 \mathrm{~h}$. Afterwards the solvent was slowly released under isothermal conditions. The resulting brittle monolithic aerogel was calcined for $2 \mathrm{~h}$ at $973 \mathrm{~K}$ in order to remove the remaining traces of solvents, and ball milled at $250 \mathrm{rpm}$ for $1 \mathrm{~h}$ in an agate mortar. The product obtained at this stage, that will be referred to as the as-prepared state, is a white powder consisting in $0.2-50 \mu \mathrm{m}$ particles of partially crystallized YSZ with low levels of fluorescence emission intensity (see figure 1(b)).

\subsection{Heat treatments}

The sensitivity of the phosphor to the exposure at high temperature was investigated by heat treating samples of the as-prepared powder at different temperatures in the range $1173-1423 \mathrm{~K}$ with $50 \mathrm{~K}$ steps. This temperature range corresponds to the highest operating temperature range of YSZbased thermal barrier coatings in gas turbines. $6 \times 3.5 \mathrm{~mm}^{2}$ porcelain crucibles were filled with $1 \mathrm{~g}$ of powder and calcined in air under isothermal conditions for 15 minutes in a box furnace (Nabertherm), followed by quenching down to room temperature in open air. This duration of exposure was selected in order to produce significant evolution of the fluorescence properties over the whole temperature range of interest, while remaining close to the exposure times typical of temperature sensing procedures involving thermochromic paints $(3-5 \mathrm{~min})[5,6,8]$. For each treatment, the temperature of exposure was monitored using two S-type thermocouples located above and as close as possible to the sample. Some samples of the as-prepared powder were also annealed for $2 \mathrm{~h}$ at $1373 \mathrm{~K}$ in air to ensure the complete crystallization of the material into the metastable tetragonal phase of YSZ.

\subsection{Characterization}

Structural analysis of YSZ powder samples were performed by X-rays diffraction measurements (XRD). XRD patterns were collected by scanning the angular range from $25^{\circ}$ to $100^{\circ}$ with a PANalytical X'Pert diffractometer equipped with a $\mathrm{X}$ 'Celerator linear detector using $\mathrm{Cu} \quad \mathrm{K}_{\alpha} \quad(\lambda$ $\left(\mathrm{CuK}_{\alpha 1}\right)=1.5406 \AA$ ) as the $\mathrm{X}$-ray source.

The fluorescence studies were performed using a frequency doubled, continuous wave diode-pumped $\mathrm{Nd}$ :YAG laser irradiating at $532 \mathrm{~nm}$ with maximum power of $1.1 \mathrm{~W}$ (CNI laser) as an excitation source. For emission spectra and intensities, the fluorescence signal of each sample was recorded at room temperature over the $400-700 \mathrm{~nm}$ range with an Ocean Optics USB2000+ spectrometer equipped with a $1000 \mu \mathrm{m}$ optical fiber. A high-pass filter with a cutoff wavelength of $535 \mathrm{~nm}$ was used to attenuate the contribution of the laser line at $532 \mathrm{~nm}$.

For the determination of the fluorescence lifetime of the $\mathrm{Er}^{3+}$ ions emission line at $562 \mathrm{~nm}$, an acousto-optic modulator operating in digital mode (1250C model, Isomet) and a diaphragm were used to generate $\sim 20 \mu$ s long excitation pulses on the sample from the continuous laser beam. The fluorescence intensity decay after each pulse was collected using a Si photomultiplier (SensL) equipped with a narrow band-pass interference filter centered on $560 \mathrm{~nm}$ (FWHM $\sim 10 \mathrm{~nm}$ ). The signal was then digitized and averaged over 128 pulses with a semi-numerical oscilloscope (Fluke) computer-monitored. After subtraction of the constant offset term, each recorded decay $I(t)$ was fitted using the nonlinear least square Levenberg-Marquardt algorithm [45, 46] to a mono-exponential model of the form given in equation (1):

$$
I(T)=I_{0} e^{-\frac{t}{\tau}}
$$

where $I_{0}$ is a pre-exponential constant and $\tau$ is the decay time. For each exponential decay fit, an iteratively adapted fitting window was used (sets between $t=0$ and $t=10 \tau$ ), according to the method proposed by Brübach et al in reference [47]. All measurements were performed at room temperature.

\section{Results}

\subsection{Effects of temperature of exposure on the crystal structure of $Y S Z$}

The effects of temperature after 15 minutes long heat treatments on the crystallinity of the YSZ: $\mathrm{Er}^{3+}$ powders were investigated by XRD. Figure 3 shows the evolution of the diffraction patterns of samples exposed to various temperatures in the range $1173-1423 \mathrm{~K}$. They remain in all cases typical of the metastable tetragonal phase of YSZ. However, as discussed in section 2 (see figure 2), relatively broad and weak diffraction peaks are observed in the diffraction pattern of the as-prepared powder, indicating that the sample remains in a partially crystallized state due to the relatively low temperature involved in its fabrication ( $973 \mathrm{~K}$ for $2 \mathrm{~h}$ ). It can be noticed that these peaks steadily become sharper and more intense as the temperature of exposure increases up to $1423 \mathrm{~K}$, as the result of the enhancement of crystallinity and the growth of YSZ crystals [31, 33, 37].

The effects of the heat treatments on crystallinity are already clearly marked at $1173 \mathrm{~K}$, at which a $42 \%$ intensity increase and a 20\% FWHM reduction is for instance observed on the main $\left(\begin{array}{lll}1 & 0 & 1\end{array}\right)_{\mathrm{t}^{\prime}}$ diffraction peak at $2 \theta=30^{\circ}$. In addition, the comparison of peaks intensity and FWHM with those of the assumed final state obtained after $2 \mathrm{~h}$ of annealing at $1373 \mathrm{~K}$ shows that the crystallization process is not completed after 15 minutes at $1423 \mathrm{~K}$. Indeed, the maximum intensity of the strongest peak at $2 \theta=30^{\circ}$ corresponding to the reflection by the family of atomic planes $\left(\begin{array}{lll}1 & 0 & 1\end{array}\right)_{\mathrm{t}^{\prime}}$, taken as an arbitrary 


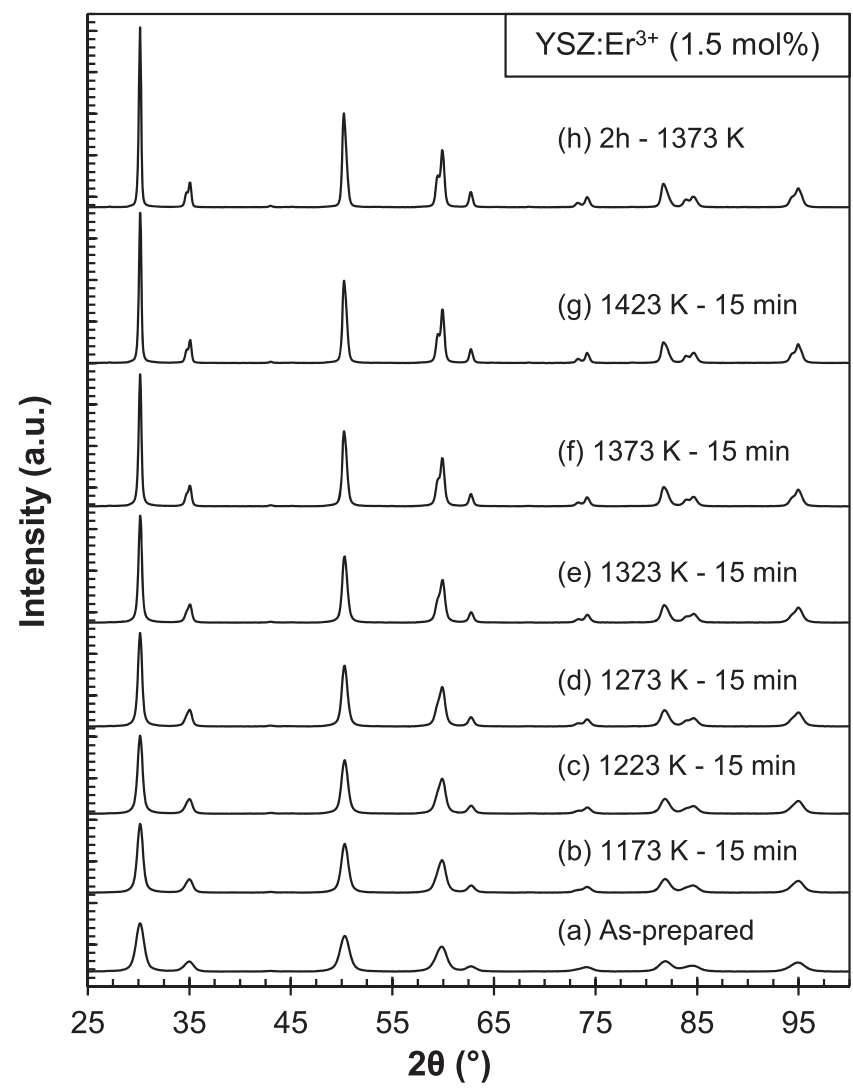

Figure 3. X-ray diffraction patterns of $1.5 \mathrm{~mol} \%{\mathrm{YSZ}: \mathrm{Er}^{3+}}^{3+}$ aerogel powder samples (a) as-prepared and calcined (b)-(g) for $15 \mathrm{~min}$ at various temperatures between 1173 and $1423 \mathrm{~K}$, (h) $2 \mathrm{~h}$ at $1373 \mathrm{~K}$ for $2 \mathrm{~h}$, showing increase of crystallinity with temperature.

indicator of the degree of crystallinity, represents only $83 \%$ of the intensity observed in the final state.

Therefore, $15 \mathrm{~min}$ long heat treatments induce a significant and permanent enhancement of the crystallinity over the whole range 1173-1423 K, whose extent appears to be a function of the temperature of exposure. It should also be noted that isothermal heat treatments at a fixed temperature of $1423 \mathrm{~K}$ and for various exposure times ranging between 5 and 30 min revealed that more than $80 \%$ of the crystallinity changes occurred during the first 5 min of the treatment, after which the evolution with time was much slower.

\subsection{Effects of temperature of exposure on the fluorescence properties}

4.2.1. Fluorescence intensity. Figure 4(a) illustrates the evolution of the relative fluorescence emission spectra of YSZ: $\mathrm{Er}^{3+}$ samples with annealing temperature under the excitation of a green laser emitting at $532 \mathrm{~nm}$. It can be observed that the relative intensity of the two main emission peaks at 545 and $562 \mathrm{~nm}$ increases consistently with increasing temperature, up to a factor of 43-48 after $15 \mathrm{~min}$ at $1423 \mathrm{~K}$. Calibration curves relating the integrated intensity of both above mentioned peaks to temperature are plotted in figure $4(b)$.

The relative integrated intensity for both emission lines, conveying the amplification of the initial intensity observed
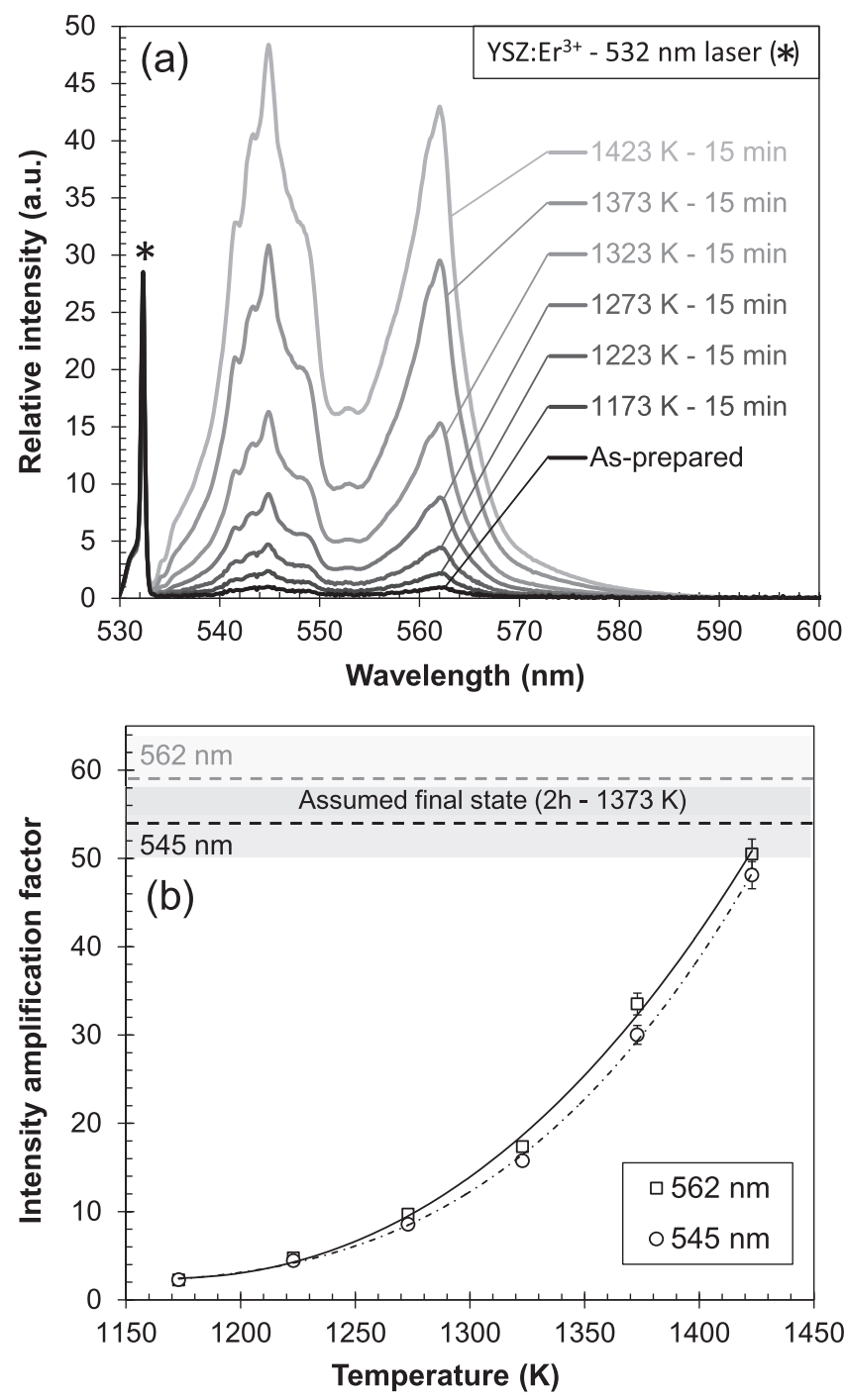

Figure 4. (a) Fluorescence emission spectra of $\mathrm{YSZ}: \mathrm{Er}^{3+}$ calcined for $15 \mathrm{~min}$ at different temperatures and (b) evolution of relative emission peak intensity of the 545 and $562 \mathrm{~nm}$ transition lines with temperature. Intensities are normalized with the maximum intensity of the as-prepared powder. Plotted lines in (b) correspond to the fit of the experimental data points with a 3 rd order polynomial.

with the as-prepared sample, increases steadily from a factor of $\sim 2$ to $\sim 43-48$ between 1173 and $1423 \mathrm{~K}$, confirming the significant temperature sensitivity of this fluorescence parameter across this whole range. The sensitivity is in addition observed to increase with temperature and is significantly greater in the 1373-1423 K range. Fits of the experimental data points with an empirical 3rd degree polynomial, plotted on figure 4(b) as solid lines, give a fair approximation of the observed monotonic increase of the intensity with temperature.

4.2.2. Fluorescence lifetime. Figure 5 shows the evolution of the fluorescence lifetime of the $562 \mathrm{~nm}$ emission line of $\mathrm{Er}^{3+}$, measured at room temperature, with temperature of exposure.

It exhibits an almost linear increase from 28 to $44 \mu \mathrm{s}$ between 1173 and $1373 \mathrm{~K}$. The fluorescence lifetime of all calcined samples is also significantly higher than for the as- 


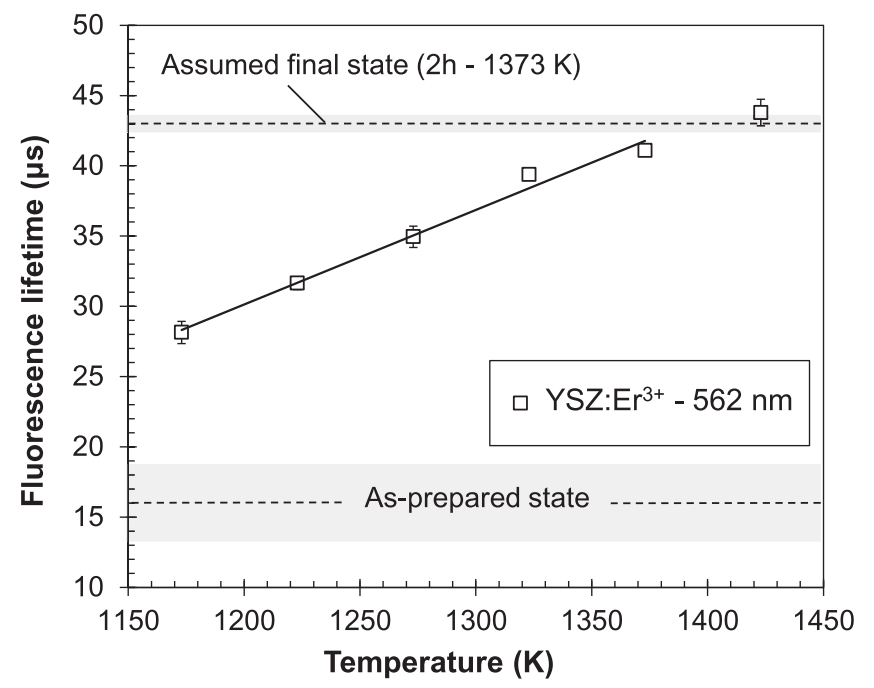

Figure 5. Temperature dependency of the YSZ: $\mathrm{Er}^{3+}$ fluorescence lifetime from the emission line at $562 \mathrm{~nm}$ for 15 minute-long heat treatments.

prepared sample $(\sim 16 \mu \mathrm{s})$. However, the decay time obtained with the sample treated to $1423 \mathrm{~K}$ is identical to that of the assumed fully crystallized sample $(\sim 43 \mu \mathrm{s})$. These results suggest that the sensitivity to temperature of the YSZ: $\mathrm{Er}^{3+}$ powder, for $15 \mathrm{~min}$ long heat treatments, ranges from a maximum temperature between 1423 and $1373 \mathrm{~K}$ to at least $1173 \mathrm{~K}$, and might extend to temperature lower than $1173 \mathrm{~K}$. The fluorescence decay time therefore appears to be a suitable complementary indicator of thermal history, which shows the advantage over absolute intensity to be relatively insensitive to experimental measurement conditions [48, 49].

\subsection{Intensity ratio method}

As a credible alternative to thermochromic paints, it is desirable that fluorescent thermal history sensors can allow rapid evaluation of temperature fields over large areas of components under investigation. Although decay time is intrinsically independent from most of experimental conditions, lifetime mapping with fast decaying phosphors such as YSZ: $\mathrm{Er}^{3+}(\tau<50 \mu \mathrm{s})$ is in practice significantly trickier than intensity mapping. Intensity maps can indeed be easily recorded using experimental setups similar to those commonly used with temperature sensitive paints, involving continuous light sources and standard CCD cameras. Furthermore, intensity based methods would allow to take advantage of the particularly strong temperature sensitivity of the main emission lines of YSZ: $\mathrm{Er}^{3+}$ between 1173 and $1423 \mathrm{~K}$ (figure 4(b)).

In order to overcome the dependency of absolute intensities over experimental factors, mostly related to the excitation source, the sample and the detection system, a typical intensity ratio approach $[48,49]$ is proposed. A temperature sensitive parameter $I_{r}$ is defined as the ratio of the temperature sensitive emission line of the YSZ: $\mathrm{Er}^{3+}$ marker at $562 \mathrm{~nm}$ $\left(I_{\mathrm{Er} / 562}(T)\right)$ and the temperature insensitive emission line at $606 \mathrm{~nm}$ of an annealed YSZ:Eu ${ }^{3+}$ reference phosphor powder in a fully crystallized state $\left(I_{\mathrm{Eu} / 606}\right)$, according to the

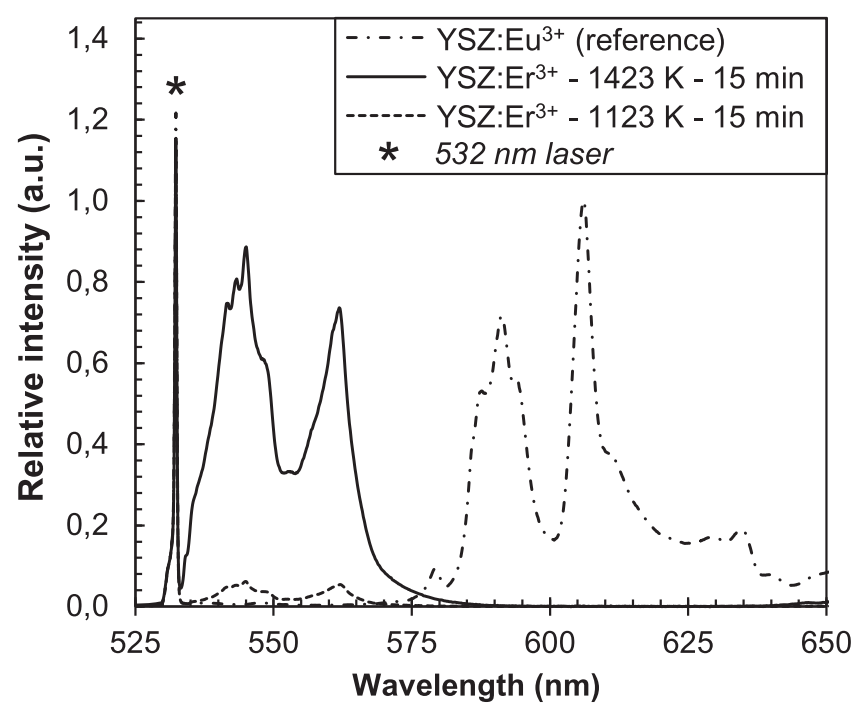

Figure 6. Comparison of the visible emission spectra of YSZ:Er ${ }^{3+}$ (temperature sensitive phosphor) and YSZ:Eu ${ }^{3+}$ (used as a reference) treated at various temperatures.

expression given in equation (2):

$$
I_{r}(T)=\frac{I_{\mathrm{Er} / 562}(T)}{I_{\mathrm{Eu} / 606}} .
$$

This latter phosphor was chosen amongst the phosphors available at the time in order to illustrate the concept of a composite fluorescent thermal history sensor. Easily synthesized through the sol-gel route described in the experimental section and annealed for $2 \mathrm{~h}$ at $1373 \mathrm{~K}$ to ensure complete crystallization, it exhibits strong emissions lines at 589 and $606 \mathrm{~nm}$ well distinct from those of $\mathrm{Er}^{3+}$ ions (figure 6). It also combines the advantages of being chemically compatible with YSZ: $\mathrm{Er}^{3+}$ and having an excitation band covering the emission wavelength of the $532 \mathrm{~nm}$ laser source [50], that can therefore be used to excite both phosphors simultaneously. High temperature stability tests carried out on sintered disks of YSZ: $\mathrm{Eu}^{3+}$ aerogel powders also showed that, once full crystallization is achieved following $2 \mathrm{~h}$ of exposure at $1373 \mathrm{~K}$, no significant variation in the absolute intensity of its two main emissions is observed even after $500 \mathrm{~h} 1423 \mathrm{~K}$ [22]. It is therefore expected that no further changes will occur within the powder that would affect the emitted intensity after a 15 minutes heat treatment even at $1423 \mathrm{~K}$, except for some very limited coarsening of the average crystallite size with no significant impact on intensity for such a short duration. The $I_{r}$ parameter should thus provide a robust indicator of the thermal history in the range $1173-1423 \mathrm{~K}$, i.e. it should be insensitive to small variations in most of the measurement conditions such as distance of observation, viewing angle and inhomogeneities of the illumination zone.

In order to validate the relevance of the $I_{r}$ parameter, a preliminary study was carried out on the YSZ: $\mathrm{Er}^{3+}$ powders previously investigated and a unique YSZ: $\mathrm{Eu}^{3+}$ powder sample (calcined for $2 \mathrm{~h}$ at $1373 \mathrm{~K}$ to ensure full crystallization), whose role was to reproduce the ideal behavior of the reference. Due to the limited quantity of reference powder 


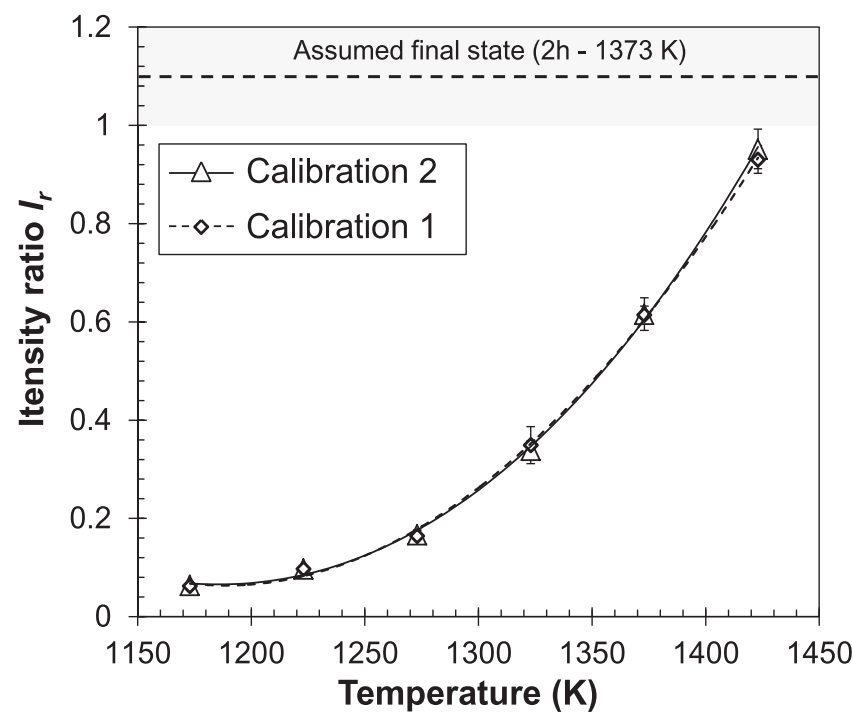

Figure 7. Evolution with temperature of the intensity ratio $I_{r}$ calculated using equation (2) for two different experimental setups having slightly different observation distances and volumes of powder probed.

available at the time, reference samples could indeed not be subjected to the same 15 min heat treatment as YSZ: $\mathrm{Er}^{3+}$ samples. The ratio was thus built, for each data point, from the signal recorded during measurements immediately consecutive on the corresponding YSZ: $\mathrm{Er}^{3+}$ sample and a unique reference respectively. These conditions remain nevertheless consistent with the expected temperature insensitive behavior of the ideal reference. For the fluorescence measurements, a $10 \mathrm{~nm}$ wide integrating window centered on the maximum of each peak was used in order to obtain a detection window similar to that considered when using a CCD camera equipped with a typical narrow band-pass filter ( $\sim 10 \mathrm{~nm}$ FWHM).

Figure 7 shows the evolution of $I_{r}$ with temperature for two different measurement configurations slightly differing by the volume of powder probed (laser beam diameter of (1) $1 \mathrm{~mm}$ and (2) $1.2 \mathrm{~mm}$ ) and by the distance of observation (distance between the optical fiber and the sample of (1) $20 \mathrm{~cm}$ and (2) $25 \mathrm{~cm}$ ).

Both calibration curves exhibit a steady increase with temperature well approximated by a third degree polynomial as observed with absolute intensities (see figure 4(b)). More importantly, no significant differences are observed between the two curves in the whole range 1173-1423 K. Although the approach only remains an approximation of the concept of a mixed fluorescent $\mathrm{YSZ}: \mathrm{Er}^{3+} / \mathrm{YSZ}: \mathrm{Eu}^{3+}$ marker, these results are promising in terms of the robustness of the $I_{r}$ parameter for small variations in the observation distance and the number of luminescent centers excited.

\subsection{Thermal stability of the temperature sensing capabilities}

Previous results have demonstrated the strong sensitivity to temperature of exposure of YSZ: $\mathrm{Er}^{3+}$ and composite YSZ: $\mathrm{Er}^{3+} / \mathrm{YSZ}^{2} \mathrm{Eu}^{3+}$ phosphors in the range 1173-1423 K. The practical application of these markers however requires that they can be successfully integrated into coatings deposited at
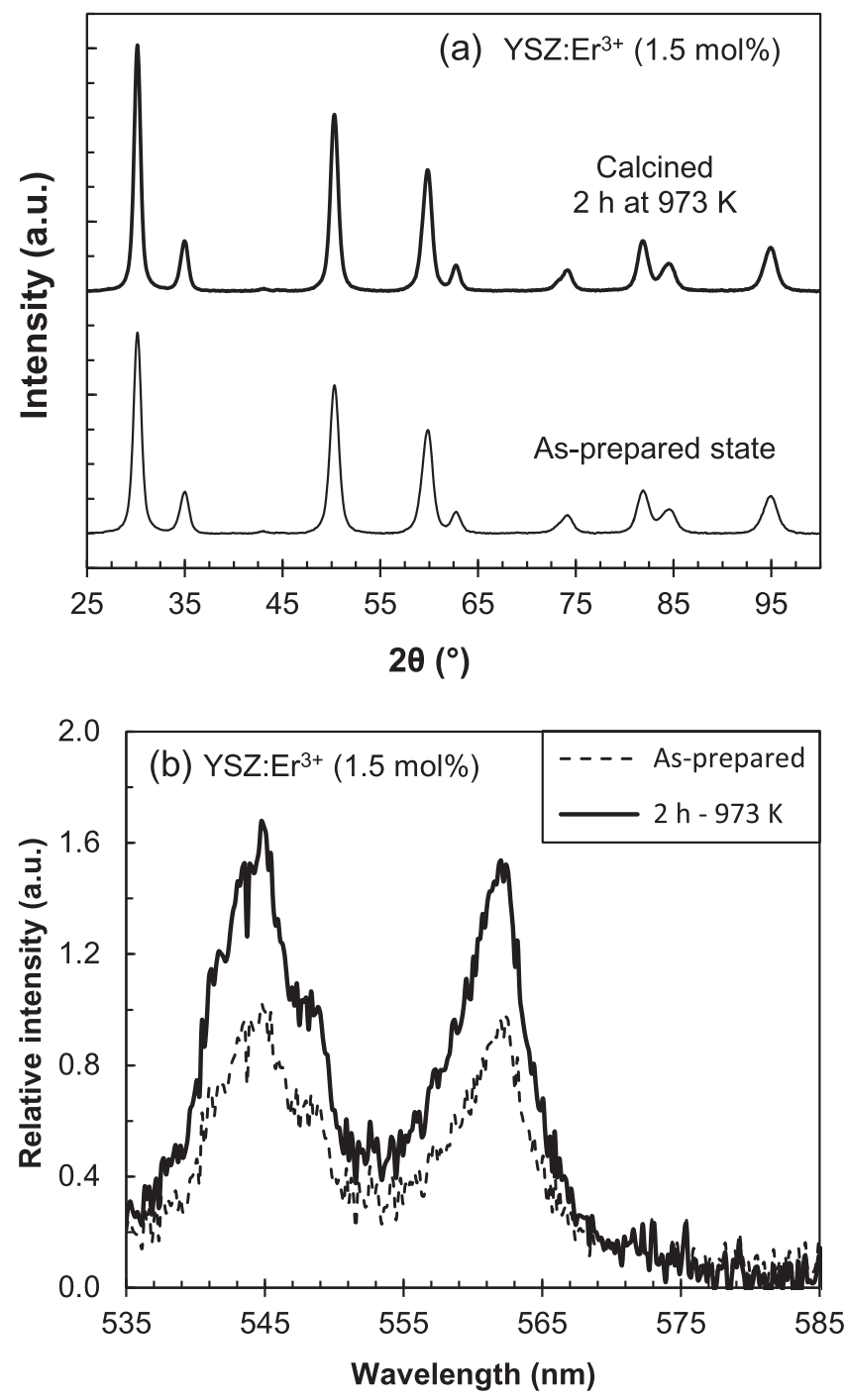

Figure 8. Comparison of (a) x-ray diffraction patterns and (b) fluorescence spectra of YSZ: $\mathrm{Er}^{3+}$ powder in the as-prepared state and calcined $2 \mathrm{~h}$ at $973 \mathrm{~K}$ with heating and cooling speeds of $100 \mathrm{~K} \mathrm{~h}^{-1}$

the surface of tested components. These coatings must sustain potentially harsh conditions during the short testing times, including high temperature, thermal shocks and mechanical stress for moving parts in engines. Numerous organic and inorganic binders exist for the integration of luminescent markers for high temperature applications [51], however thermal history sensors such as YSZ: $\mathrm{Er}^{3+}$ require that processing temperature and duration of exposure of the coating do not prematurely activate the temperature-driven mechanisms at the origin of its temperature sensing capability. The thermal stability at moderate temperature of the temperature sensitivity of the sensor was thus evaluated. Figure 8 illustrates the $\mathrm{x}$-ray diffraction patterns and the emission spectra of YSZ: $\mathrm{Er}^{3+}$ powders in the as-prepared state and after an additional heat treatment for $2 \mathrm{~h}$ at $973 \mathrm{~K}$ with heating and cooling speeds of $100 \mathrm{~K} \mathrm{~h}^{-1}$.

The latter treatment does not induce significant enhancement of the crystallinity (figure 8(a)) or emission intensity increase $(\sim 60 \%)$ as compared to the changes 
observed previously in figures 3 and 4(b) after 15 minutes between 1173 and $1423 \mathrm{~K} \quad(\sim 100 \%-4500 \%$ intensity increase). It is therefore concluded that the temperature sensing capabilities remain unaffected by heat treatments up to $973 \mathrm{~K}$ for $2 \mathrm{~h}$.

\section{Discussion}

Figures 4 and 5 show that both emission intensity and decay time of the YSZ:Er ${ }^{3+}$ phosphor synthesized by a sol-gel route exhibit a strong dependency on the temperature of exposure in the range $1173-1373 \mathrm{~K} / 1423 \mathrm{~K}$ for 15 minute-long heat treatments, that would be suitable for recording the temperature of past thermal events achieved under controlled conditions. As discussed in section 2, these permanent evolutions are assumed to be related to temperature-driven changes within the host matrix induced by the enhancement of the crystallinity, whose extent is a function of the temperature of exposure in that range (figure 3 ). These changes most likely include the uniformization of the crystal field, the removal of quenching sites such as crystal defects and residual organic groups to which $\mathrm{Er}^{3+}$ ions are particularly sensitive [38], as well as the growth of YSZ crystallites [12, 33, 34, 52].

The fact that the fluorescence lifetime of the emission at $562 \mathrm{~nm}$ already has converged to its final state value after 15 minutes at $1373 \mathrm{~K}$ (figure 5) while intensity and crystallinity continue to improve up to $1423 \mathrm{~K}$ (figures 3 and 4(a)) indicates that the conditions to reach the converged decay time are met before the assumed complete crystallization of the material has occurred. This is probably due to final stages likely being dominated by YSZ crystallites growth which affect absorption of excitation energy and not radiative transition probabilities, thus having little impact on decay time. The relative independence of the decay time on the number of active $\mathrm{Er}^{3+}$ ions (i.e. on the energy absorbed by crystallites and on the total volume of material where the conditions for the $\mathrm{Er}^{3+}$ ions to emit are reunited) is therefore assumed to be the reason behind the difference in behavior between the evolution of the decay time (moderate linear increase by a factor of 2.7 up to $1373 \mathrm{~K}$, figure 4(b)) and the evolution of the emission intensity (strong increase, following a 3rd degree polynomial, by a factor of 50 up to at least $1423 \mathrm{~K}$, figure 5).

The fluorescence characteristics of the two main emission peaks of YSZ: $\mathrm{Er}^{3+}$ offer wide measuring and dynamic ranges between 1173 and $1423 \mathrm{~K}$ and $1173-1373 \mathrm{~K}$ in which intensity and fluorescence lifetime increase monotonously (figures 4 and 5). The empirical models determined with the fits of the experimental data points (a 3rd order polynomial for emission intensity, figure 4(b), and a linear model for decay time, figure 5) were used to calculate noise-equivalent temperatures (NET) as a first estimation of the theoretical resolution of the marker, using the expression given in equation (3):

$$
\mathrm{NET}=\frac{\sigma_{i}}{S_{T_{i}}}
$$

Parameters $S_{T i}$ correspond to the sensitivity of the marker in a small interval around the temperature $T_{i}$, straightforwardly derived from the empirical expressions obtained with the fit of the experimental data points. Parameters $\sigma_{i}$ are the expanded uncertainties of the emission intensity or decay time measurement at $T_{i}$. For each sample, it corresponds to the standard deviation obtained from 30 repetitions of single measurements for a unique position of the sample weighted by a coverage factor of 2 . Under the present experimental conditions, the NET values obtained are comprised between 0.7 and $0.3 \mathrm{~K}$ in the range $1223-1423 \mathrm{~K}$ for intensity measurements, and between 6 and $2 \mathrm{~K}$ in the range $1173-1423 \mathrm{~K}$ for decay time measurements, suggesting that the theoretical resolution of the marker would be much greater than the resolution of most thermochromic pigments in that temperature range, typically limited to one to four color transitions [6-8]. It should be noted though that, at this stage, these NET values remain a first approximation of the resolution based on a limited number of experimental data points. Nevertheless, these results confirm the relevance of YSZ: $\mathrm{Er}^{3+}$ fluorescence emission and decay time as thermal history indicators suitable for high temperature sensing. The high sensitivity of emission intensity at temperatures higher than $1273 \mathrm{~K}$ (increase of intensity per degree increment corresponding to $32 \%$ to that of the as-prepared material around $1373 \mathrm{~K}$, figure 4(b)) is especially interesting for precise temperature sensing on critical components applied to the design of high temperature systems operating in that range, such as gas turbines.

It can be seen from figure 5 that the sensitivity range to temperature of the lifetime decay for 15 minutes long heat treatment ranges from a maximum temperature between 1423 and $1373 \mathrm{~K}$ to at least $1173 \mathrm{~K}$, and might extend to temperature lower than $1173 \mathrm{~K}$ (figure 5). The fluorescence decay time, which shows the advantage over absolute intensity to be relatively insensitive to experimental measurement conditions $[48,49]$ therefore appears to be a suitable complementary indicator of thermal history for OD measurements, but could also improve or extend the overall thermal history sensitivity range of YSZ: $\mathrm{Er}^{3+}$ if combined with intensity measurements. More generally, it is expected that the whole temperature sensitivity range could be shifted to higher or lower temperature to adjust to the targeted desired application by increasing or reducing the exposure time respectively, in relation with the time dependency of the extent of crystallinity enhancement under isothermal conditions [12, 53, 54]. Reduction of the exposure time to five minutes or less, in order to keep up with actual testing procedures using thermochromic paints, is assumed to be possible and would shift the temperature sensitive range of the marker to higher temperatures, with, as a consequence, readouts more sensitive to time related errors. Investigation of the effect of the exposure time showed indeed that, as for crystallinity changes, most of the intensity increase is achieved within the first five minutes of exposure at high temperature $(\sim 75 \%$ of the final intensity is reached after 5 minutes for a 15 minutes heat treatment at $1423 \mathrm{~K}$ ).

The robustness of the ratio $I_{r}$ to small variations in the observation conditions (figure 7), suggest that this intensity ratio method, using a compatible temperature insensitive 
reference phosphor such as fully crystallized YSZ:Eu ${ }^{3+}$, is a promising approach to take advantage of the strong temperature sensitivity of the emission intensity for off-line temperature mapping applications. Foreseen main limiting factors regarding the robustness of the $I_{r}$ ratio that require further investigation include in particular the possible differences in the optical properties of the host YSZ matrix at the different wavelength investigated $\left(562 \mathrm{~nm}\right.$ for $\mathrm{Er}^{3+}$ and $606 \mathrm{~nm}$ for $\mathrm{Eu}^{3+}$ ), and the effective thermal stability of the YSZ:Eu ${ }^{3+}$ reference when blended with the YSZ: $\mathrm{Er}^{3+}$ marker and calcined for $15 \mathrm{~min}$ in the range $1173-1423 \mathrm{~K}$. Other more convenient references could also be explored, such as $\mathrm{Al}_{2} \mathrm{O}_{3}$ : $\mathrm{Cr}^{3+} \cdot \mathrm{Cr}^{3+}$ ions indeed produce very strong fluorescence and have a broader excitation peak than lanthanide ions. Therefore, only a small amount of reference powder would need to be mixed in, and an excitation wavelength at $514 \mathrm{~nm}$ could be used, which would excite stronger fluorescence from $\mathrm{Er}^{3+}$ ions than at $532 \mathrm{~nm}$ [22].

Finally, the investigation of the thermal stability of the YSZ: $\mathrm{Er}^{3+}$ as-prepared powder (figure 8) has shown that the material retains almost all of its temperature recording capabilities after a $2 \mathrm{~h}$ long heat treatment at $973 \mathrm{~K}$. Compatible binders with processing temperature up to $973 \mathrm{~K}$ for $2 \mathrm{~h}$ therefore appear to be appropriate candidates for the integration of the investigated YSZ: $\mathrm{Er}^{3+}$ and YSZ:Eu ${ }^{3+}$ phosphors in temperature sensitive coatings. Both the sensing YSZ: $\mathrm{Er}^{3+}$ powder and the annealed YSZ: $\mathrm{Eu}^{3+}$ powder (or any other relevant reference) would be mixed into a transparent high temperature binder and applied on the parts with an air brush, as for typical fluorescent coatings used for phosphor thermometry [51]. The satisfactory thermomechanical properties of YSZ coatings, widely used in thermal barrier coating applications up to $1473 \mathrm{~K}[55,56]$, also offer the possibility to directly deposit the phosphors as coatings or using a YSZ host matrix, similarly to what is done for fluorescent thermal barrier sensor coatings [21, 50, 57]. The chemical compatibility of the marker with the reference and the matrix could indeed facilitate the sintering of the coating as a morphologically uniform single layer (see sol-gel TBC sensors in reference [21]) at relatively low temperature $(<973 \mathrm{~K})$. Therefore, low temperature deposition processes of YSZ coatings, such as the dip-coating process developed by the CIRIMAT in collaboration with the ICA $[20,21]$ and other soft chemistry processes followed by sintering at a temperature lower than $973 \mathrm{~K}$ are expected to be relevant and promising solutions for the deposition of $\mathrm{YSZ}: \mathrm{Er}^{3+} / \mathrm{YSZ}$ : $\mathrm{Eu}^{3+}$ thermal history sensor coatings. A sol-gel method involving air-spraying at room temperature of a sol loaded with particles followed by a heat treatment at a temperature below $700{ }^{\circ} \mathrm{C}$ is currently under investigation. Such coatings could be especially interesting for being used on component already coated with YSZ-based thermal barrier coatings in gas turbines, both for a potentially enhanced adherence and for their temperature sensing range (1223-1423 K) covering typical operating range of such parts $[55,56]$. Feasibility of sol-gel deposition of $\mathrm{YSZ}: \mathrm{Er}^{3+} / \mathrm{YSZ}: \mathrm{Eu}^{3+}$ coatings and associated mechanical adherence will be investigated in future a work.

\section{Conclusion}

The knowledge of temperature to which components are subjected in service is essential to anticipate and prevent failure issues during the design phase of many high temperature systems [1-4]. This paper discussed the concept of fluorescent thermal history sensor as an alternative to thermochromic paints, and confirmed the potential as such of $\mathrm{Er}^{3+}$-doped YSZ powders produced by a sol-gel route, whose fluorescence properties appear to be a function of the crystallinity of the YSZ host matrix. The continuous, temperaturedriven enhancement of the crystallinity of YSZ: $\mathrm{Er}^{3+}$ powder samples observed after 15 minutes long heat treatments between $1173 \mathrm{~K}$ and $1423 \mathrm{~K}$ induces indeed substantial and consistent increases of their green emission intensity and fluorescence decay time in the ranges $1223 \mathrm{~K}-1423 \mathrm{~K}$ and $1173 \mathrm{~K}-1373 \mathrm{~K}$ respectively. These strong temperature dependencies are assumed to be suitable for off-line temperature sensing with an estimated theoretical resolution for those temperatures ranging between 0.3 and $1 \mathrm{~K}$ and between 6 and $2 \mathrm{~K}$ for intensity and decay time respectively, surpassing the resolution of actual thermochromic paints in that temperature range. It is also assumed possible to adjust the sensitivity ranges through exposure duration changes. Preliminary investigations confirmed the potential of an intensity ratio approach, using a red emitting, temperature insensitive YSZ:Eu ${ }^{3+}$ reference, as a robust method regarding small variations in experimental measurement conditions for future applications in off-line temperature mapping. Finally, the thermal stability of the YSZ: $\mathrm{Er}^{3+}$ marker up to $973 \mathrm{~K}$ for a short period of time $(2 \mathrm{~h})$ is promising for its integration within coatings for practical thermal history sensing applications, such as sol-gel deposited YSZ-based coatings $[20,21]$ that will be investigated in a future work.

\section{Acknowledgments}

The authors would like to thank Guillaume Pujol and Fabien Blas for their kind assistance with the materials synthesis and the deposition of the coatings. Thanks to the École des Mines d'Albi and the Carnot CIRIMAT Institute for their material and financial contribution to this work.

\section{References}

[1] Viswanathan R 1989 Damage Mechanisms and Life Assessment of High Temperature Components (Materials Park, OH: ASM International)

[2] Kurz R and Brun K 2000 Degradation in gas turbine systems J. Eng. Gas Turbines Power 123 70-7

[3] Hihara L H, Adler R P I and Latanision R M 2013 Environmental Degradation of Advanced and Traditional Engineering Materials (Boca Raton, FL: CRC Press)

[4] Bar-Cohen Y 2014 High Temperature Materials and Mechanisms (Boca Raton, FL: CRC Press)

[5] Chamberlain J R 1991 Temperature indicating paint and method of preparing a specimen with the same US Patent 5008136A 
[6] Hodgkinson E and Watson H 2004 Temperature indicating paint US Patent 6673271 B2

[7] Watson H M L 2004 Temperature indicating paint US Patent 6682665 B2

[8] Hughes M 2011 Temperature indicating paint US Patent 8012375 B2

[9] Salek G, Demourgues A, Jubera V, Garcia A and Gaudon M $2015 \mathrm{Mn}^{2+}$ doped $\mathrm{Zn}_{3}\left(\mathrm{PO}_{4}\right)_{2}$ phosphors: irreversible thermochromic materials useful as thermal sensors $\mathrm{Opt}$. Mater. 47 323-7

[10] Choy K-L, Heyes A L and Feist J P 2009 Thermal barrier coating with thermoluminescent indicator material embedded therein US Patent 7510776 B2

[11] Feist J P, Nicholls J R and Heyes A L 2011 Determining thermal history of components US Patent 20110069735 A1

[12] Rabhiou A, Feist J, Kempf A, Skinner S and Heyes A 2011 Phosphorescent thermal history sensors Sensors Actuators 169 18-26

[13] Heyes A L, Rabhiou A, Feist J P and Kempf A 2013 Thermal history sensing with thermographic phosphors AIP Conf. Proc., Temperature: Its Measurement And Control In Science And Industry, Volume 8: Proc. 9th Int. Temperature Symp. (New York: AIP) pp 891-6

[14] Stenders D, Karadagli I, Pflitsch C and Atakan B 2014 Sol-gel deposited thermographic phosphors as possible thermal history coatings IET ISA 60th Int. Instrumentation Symp. 2014 pp 1-6

[15] Feist J P, Karmakar Biswas S, Pilgrim C, Sollazzo P Y and Berthier S 2015 Off-line temperature profiling utilizing phosphorescent thermal history paints and coatings J. Turbomach. 137101003

[16] Yáñez-González Á, Ruiz-Trejo E, van Wachem B, Skinner S, Beyrau F and Heyes A 2015 A detailed characterization of $\mathrm{BaMgAl}_{10} \mathrm{O}_{17}:$ Eu phosphor as a thermal history sensor for harsh environments Sensors Actuators 234 339-45

[17] Cornu L, Duttine M, Gaudon M and Jubera V 2014 Luminescence switch of $\mathrm{Mn}$-Doped $\mathrm{ZnAl}_{2} \mathrm{O}_{4}$ powder with temperature J. Mater. Chem. C 2 9512-22

[18] Rabhiou A, Kempf A and Heyes A 2013 Oxidation of divalent rare earth phosphors for thermal history sensing Sensors Actuators B 177 124-30

[19] González Á Y, Skinner S, Beyrau F and Heyes A L 2015 Reusable thermal history sensing via oxidation of a divalent rare earth ion-based phosphor synthesized by the sol-gel process Heat Transfer Eng. 36 1275-81

[20] Pin L, Pilgrim C, Feist J, Le Maoult Y, Ansart F and Lours P 2013 Characterisation of thermal barrier sensor coatings synthesised by sol-gel route Sensors Actuators 199 289-96

[21] Copin E, Sentenac T, Le Maoult Y, Bias F, Ansart F, Vidal V and Lours P 2014 Feasibility of luminescent multilayer sol-gel thermal barrier coating manufacturing for future applications in through-thickness temperature gradient sensing Surf. Coat. Technol. 260 90-6

[22] Copin E 2015 Fonctionnalisation de barrières thermiques aéronautiques YSZ issues de la voie sol-gel : mesure de température et diagnostic de l'endommagement par fluorescence $P h D$ Thesis École Nationale Supérieure des Mines d'Albi-Carmaux

[23] Gentili D, Durso M, Bettini C, Manet I, Gazzano M, Capelli R, Muccini M, Melucci M and Cavallini M 2013 A timetemperature integrator based on fluorescent and polymorphic compounds Sci. Rep. 32581

[24] Lan Y, Wang H, Skula N, Chen X, Lu Y, Chen G and Ren Z 2015 Determination of thermal history by photoluminescence of core-shelled quantum dots going through heating events Part. Part. Syst. Charact. 32 65-71

[25] Cattaruzza E, Back M, Battaglin G and Trave E 2014 Unexpected behavior of the $1.54 \mu \mathrm{m}$ luminescence in Erdoped silica films J. Non-Cryst. Solids 401 186-90
[26] Deng T, Yan S and Hu J 2015 Effect of calcination temperature on Up-conversion photoluminescence of the GdAlO3: $\mathrm{Er}^{3+}, \mathrm{Yb}^{3+}$ phosphor ECS J. Solid State Sci. Technol. 4 R48-53

[27] Ramanathan S, Soni N C and Prasad R 1993 Crystallization behaviour of zirconia $10 \mathrm{~mol} \%$ yttria by hot-stage x-ray diffraction J. Mater. Sci. Lett. 12 122-4

[28] Málek J, Matsuda S, Watanabe A, Ikegami T and Mitsuhashi T 1995 Crystallization kinetics of zirconia-yttria gels Thermochim. Acta 267 181-94

[29] Rashad M M and Baioumy H M 2008 Effect of thermal treatment on the crystal structure and morphology of zirconia nanopowders produced by three different routes J. Mater. Process. Technol. 195 178-85

[30] Málek J 2000 Kinetic analysis of crystallization processes in amorphous materials Thermochim. Acta 355 239-53

[31] Quan Z W, Wang L S and Lin J 2005 Synthesis and characterization of spherical $\mathrm{ZrO}_{2}: \mathrm{Eu}^{3+}$ phosphors by spray pyrolysis process Mater. Res. Bull. 40 810-20

[32] Zhou Y H, Lin J, Wang S B and Zhang H J 2002 Preparation of $\mathrm{Y}_{3} \mathrm{Al}_{5} \mathrm{O}_{12}$ :Eu phosphors by citric-gel method and their luminescent properties Opt. Mater. 20 13-20

[33] Zhang J, Tang Z, Zhang Z, Fu W, Wang J and Lin Y 2002 Synthesis of nanometer $\mathrm{Y}_{2} \mathrm{O}_{3}$ :Eu phosphor and its luminescence property Mater. Sci. Eng. A 334 246-9

[34] Erdei S, Roy R, Harshe G, Juwhari H, Agrawal D, Ainger F W and White W B 1995 The effect of powder preparation processes on the luminescent properties of yttrium oxide based phosphor materials Mater. Res. Bull. 30 $745-53$

[35] Zhou Y H and Lin J 2005 Morphology control and luminescence properties of $\mathrm{YVO}_{4}$ :Eu phosphors prepared by spray pyrolysis Opt. Mater. 27 1426-32

[36] Bandi V R, Nien Y-T, Lu T-H and Chen I-G 2009 Effect of calcination temperature and concentration on luminescence properties of novel $\mathrm{Ca}_{3} \mathrm{Y}_{2} \mathrm{Si}_{3} \mathrm{O}_{12}:$ Eu phosphors $J$. Am. Ceram. Soc. 92 2953-6

[37] Martínez-Hernández A, Guzmán-Mendoza J, Rivera-Montalvo T, Sánchez-Guzmán D, Guzmán-Olguín J C, García-Hipólito M and Falcony C 2014 Synthesis and cathodoluminescence characterization of $\mathrm{ZrO}_{2}: \mathrm{Er}^{3+}$ films J. Lumin. 153 140-3

[38] Ting C-C, Chien Y-C and Sung W-F 2013 Erbium doping effects on the structural and infrared luminescence properties of $\mathrm{Gd}_{2} \mathrm{Ti}_{2} \mathrm{O}_{7}$ nanocrystals ECS J. Solid State Sci. Technol. 2 R105-10

[39] Satyanarayana T, Brik M G, Venkatramaiah N, Kityk I V, Plucinski K J, Ravikumar V and Veeraiah N 2010 Influence of crystallization on the luminescence characteristics of $\mathrm{Pr}^{3+}$ ions in $\mathrm{PbO}-\mathrm{Sb}_{2} \mathrm{O}_{3}-\mathrm{B}_{2} \mathrm{O}_{3}$ glass system J. Am. Ceram. Soc. 93 2004-11

[40] Liu C, Yu R, Xu Z, Cai J, Yan X and Luo X 2007 Crystallization, morphology and luminescent properties of YAG: $\mathrm{Ce}^{3+}$ phosphor powder prepared by polyacrylamide gel method Trans. Nonferrous Met. Soc. China 17 1093-9

[41] Venkatramu V et al 2012 Synthesis, structure and luminescence of $\mathrm{Er}^{3+}$-doped $\mathrm{Y}_{3} \mathrm{Ga}_{5} \mathrm{O}_{12}$ nano-garnets J. Mater. Chem. 22 13788-99

[42] Fenech J, Viazzi C, Bonino J-P, Ansart F and Barnabé A 2009 Morphology and structure of YSZ powders: comparison between xerogel and aerogel Ceram. Int. 35 3427-33

[43] Lecomte A, Blanchard F, Dauger A, Silva M C and Guinebretière R 1998 Synthesis and sintering of zirconium oxide aerogel J. Non-Cryst. Solids 225 120-4

[44] Shane M and Mecartney M L 1990 Sol-gel synthesis of zirconia barrier coatings J. Mater. Sci. 25 1537-44

[45] Levenberg K 1944 A method for the solution of certain nonlinear problems in least squares $Q$. Appl. Math. 2 164-8 
[46] Marquardt D 1963 An algorithm for least-squares estimation of nonlinear parameters J. Soc. Ind. Appl. Math. 11 431-41

[47] Brübach J, Janicka J and Dreizler A 2009 An algorithm for the characterisation of multi-exponential decay curves $O p t$. Lasers Eng. 47 75-9

[48] Allison S W and Gillies G T 1997 Remote thermometry with thermographic phosphors: instrumentation and applications Rev. Sci. Instrum. 68 2615-50

[49] Khalid A H and Kontis K 2008 Thermographic phosphors for high temperature measurements: principles, current state of the art and recent applications Sensors 8 5673-744

[50] Gentleman M M and Clarke D R 2004 Concepts for luminescence sensing of thermal barrier coatings Surf. Coat. Technol. 188 93-100

[51] Bruebach J, Pflitsch C, Dreizler A and Atakan B 2013 On surface temperature measurements with thermographic phosphors: a review Prog. Energy Combust. Sci. 39 37-60
[52] Silver J, Martinez-Rubio M I, Ireland T G, Fern G R and Withnall R 2001 The effect of particle morphology and crystallite size on the upconversion luminescence properties of erbium and ytterbium Co-doped yttrium oxide phosphors J. Phys. Chem. B $105948-53$

[53] Avrami M 1939 Kinetics of phase change: I. General theory J. Chem. Phys. 7 1103-12

[54] Johnson W A and Mehl R F 1939 Reaction kinetics in processes of nucleation and growth Trans. Am. Inst. Min. Metall. Eng. 135 416-42

[55] Reed R C 2006 The Superalloys: Fundamentals and Applications (Cambridge: Cambridge University Press)

[56] Bose S 2007 Thermal barrier coatings (TBCs) High Temperature Coatings (Burlington: ButterworthHeinemann) ch 7 pp 155-232

[57] Nicholls J R, Wellman R G, Steenbakker R and Feist J 2010 Self diagnostic EB-PVD thermal barrier coatings $A d v$. Sci. Technol. 72 65-74 